\title{
2-Acrylamido-2-methyl-1-propane Sulfonic Acid Based Ionic Liquid: Structural and Thermal Characterization
}

\author{
S. ÇAVUŞ* AND G. GÜL
}

Istanbul University-Cerrahpaşa, Faculty of Engineering, Department of Chemical Engineering, İstanbul, Turkey

An ionic liquid (salt structure) was prepared by neutralization of 2-acrylamido-2-methyl-1-propane sulfonic acid (AMPS) with pyridine. The characterization of the salt (AMPS-pyridine) was performed using the Fourier transform infrared spectroscopy, proton nuclear magnetic resonance spectroscopy $\left({ }^{1} \mathrm{H}-\mathrm{NMR}\right)$, X-ray diffraction, thermal gravimetric analysis, differential scanning calorimetry, and scanning electron microscopy.

DOI: 10.12693/APhysPolA.137.554

PACS/topics: ionic liquid, 2-acrylamido-2-methyl-1-propane sulfonic acid, pyridine

\section{Introduction}

Synthesis and characterization of ionic liquids (ILs) have gained growing interest because of their great number of applications such as in chemical synthesis [1,2], electrochemistry $[1,2]$, catalysis/biocatalysis $[1,2], \mathrm{CO}_{2}$ capture [3], energy storage [2,3] and magnetic responsive materials [4]. Melting point of these organic/inorganic salts is basically below $100^{\circ} \mathrm{C}[2]$. They mainly contain organic cations and inorganic or organic anions $[5,6]$. ILs exhibit outstanding properties such as negligible vapor pressure $[1,3,5]$, perfect thermal stability $[1,4]$, chemical stability [1], high conductivity $[1,5,6]$ and wide potential/electrochemical window $[1,5,6]$. ILs can be classified into two groups. Conventional or aprotic ILs include organic cations (i.e. imidazolium or pyridinium) and anions (i.e. $\mathrm{Cl}^{-}, \mathrm{Br}^{-}, \mathrm{BF}_{4}^{-}, \mathrm{PF}_{6}^{-}$). However, in general, preparation of protic ILs is based on an acid and an organic base neutralization [7]. It was reported that ILs exhibiting polymerizable character because of the presence of vinyl group on the anions (or the cations) can be used in the synthesis of gels [1].

The aim of the present study is to prepare an ionic liquid (in the solid salt form) by using a strong acidic anionic monomer, AMPS, and an aromatic amine (pyridine), and to perform its detailed characterization by the Fourier transform infrared spectroscopy (FTIR), thermal gravimetric analysis (TGA), differential scanning calorimetry (DSC), scanning electron microscopy (SEM) and X-ray diffraction (XRD) techniques.

\section{Experimental}

\subsection{Materials}

AMPS was purchased from Merck Schuchardt OHG (Germany). Acetone (Sigma-Aldrich Laborchemikalien $\mathrm{GmbH}$ ) was used as the solvent. Pyridine was of SigmaAldrich (>99\%) product.

*corresponding author; e-mail: selva@istanbul.edu.tr

\subsection{AMPS - pyridine synthesis}

AMPS-pyridine salt was synthesized at room temperature using acetone as the solvent. AMPS (10 g) was dispersed in acetone $(50 \mathrm{ml})$, and then predetermined amount of pyridine was added slowly while stirring. Formation of a homogeneous and transparent solution was observed. After evaporation of the solvent, the obtained salt in the form of solid white powder was dried first in air and then in the vacuum oven at $40{ }^{\circ} \mathrm{C}$. If ionic liquids are available in the solid form at room temperature unlike their name, they can be called "solid ionic liquids" [3]. Importantly, these type of ILs can be potential alternative to room temperature ILs for $\mathrm{CO}_{2}$ capture and energy storage [3].

\subsection{Characterization study and instrumentation}

AMPS-pyridine salt was analyzed by FTIR. FTIR bands were recorded by using the Bruker Vertex 70 FTIR Spectrometer. ${ }^{1}$ HNMR of AMPS-pyridine salt was recorded on a Varian UNITY INOVA $500 \mathrm{MHz}$ NMR spectrometer using $\mathrm{D}_{2} \mathrm{O}$ as a solvent. DSC analysis of AMPS-pyridine salt was carried out with DSC-60 Shimadzu. The analysis was completed under a scanning rate of $10^{\circ} \mathrm{C} / \mathrm{min}$, nitrogen gas flow rate of $20 \mathrm{ml} / \mathrm{min}$ and temperature range of $(-30)-100^{\circ} \mathrm{C}$. The TGA of AMPS-pyridine was conducted using Shimadzu DTG-60 instrument at a $10^{\circ} \mathrm{C} / \mathrm{min}$ heating rate in a nitrogen atmosphere $(20 \mathrm{ml} / \mathrm{min})$ from room temperature to $500^{\circ} \mathrm{C}$. X-ray diffraction analysis of AMPS-pyridine was performed with XRD (Rigaku D/Max-2200/PC). Zeiss EVO ${ }^{\circledR}$ LS10 instrument was used for SEM analysis of AMPS-pyridine salt.

\section{Results and discussion}

\subsection{FTIR characterization}

Structure of AMPS-pyridine salt was analyzed by FTIR technique and corresponding spectrum was shown in Fig. 1. Spectrum of AMPS-pyridine salt includes peaks belong to both AMPS monomer and pyridine. The peaks 


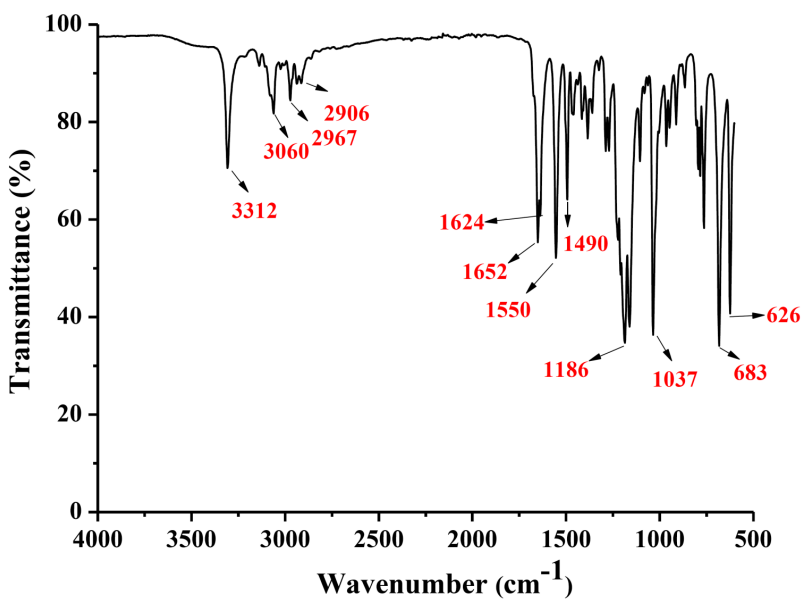

Fig. 1. FTIR spectrum of AMPS-pyridine.

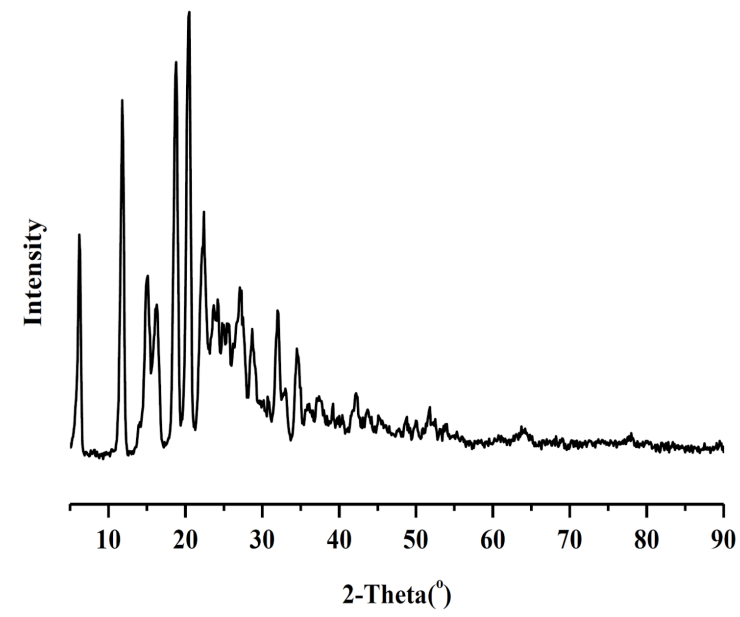

Fig. 2. XRD of AMPS-pyridine.

at 1037 and $1186 \mathrm{~cm}^{-1}$ are assignable to the stretching vibrations in sulfonic acid groups, respectively [8-10]. While the peak at $626 \mathrm{~cm}^{-1}$ shows the $\mathrm{C}-\mathrm{S}$ bond absorption [9], $-\mathrm{C}=\mathrm{C}$ bond is predicted at $1624 \mathrm{~cm}^{-1}[8,9]$. Amide II band is present at $1550 \mathrm{~cm}^{-1}$ [8]. The $\mathrm{C}-\mathrm{H}$ bond stretching of the aromatic ring is observed at about $3000-3100 \mathrm{~cm}^{-1}$ range [11]. The peaks at about 1460 and $1490 \mathrm{~cm}^{-1}$ can be related to the pyridine ring [11]. The $\mathrm{C}=\mathrm{C}$ frequency is seen at $965 \mathrm{~cm}^{-1}$, which is also characteristic for the vinyl monomers [10]. While $\mathrm{C}=\mathrm{O}$ strecthing band is seen at $1652 \mathrm{~cm}^{-1}[8,10]$, the peak at $2967 \mathrm{~cm}^{-1}$ can be attributed to $\mathrm{OH}$ bond in sulfonic acid [10]. O-H stretching is present in the region $3312 \mathrm{~cm}^{-1}$ [8].

\section{2. $X R D$ study}

XRD analysis on AMPS-pyridine was conducted to investigate its crystallization character. XRD pattern depicts that AMPS-pyridine salt is of crystalline character. Some strong diffraction peaks can be listed as at $2 \Theta=20.48^{\circ}, 18.79^{\circ}$ and $11.80^{\circ}$ (Fig. 2).

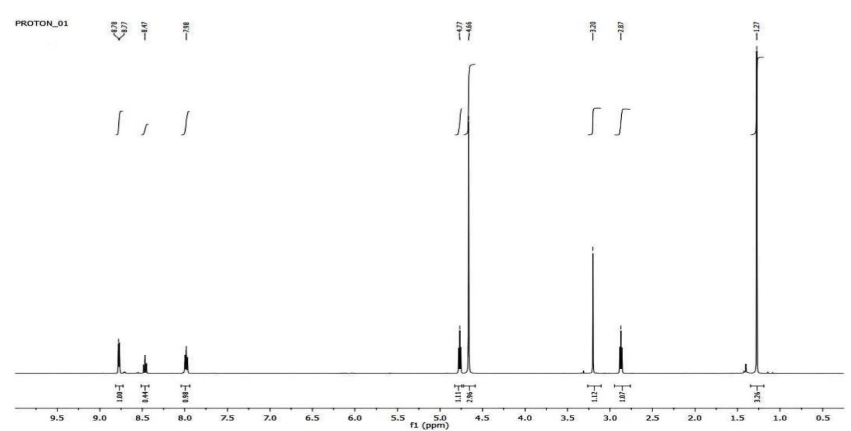

Fig. 3. ${ }^{1} \mathrm{H}-\mathrm{NMR}$ spectrum of AMPS-pyridine $\left(\mathrm{D}_{2} \mathrm{O}\right)$.

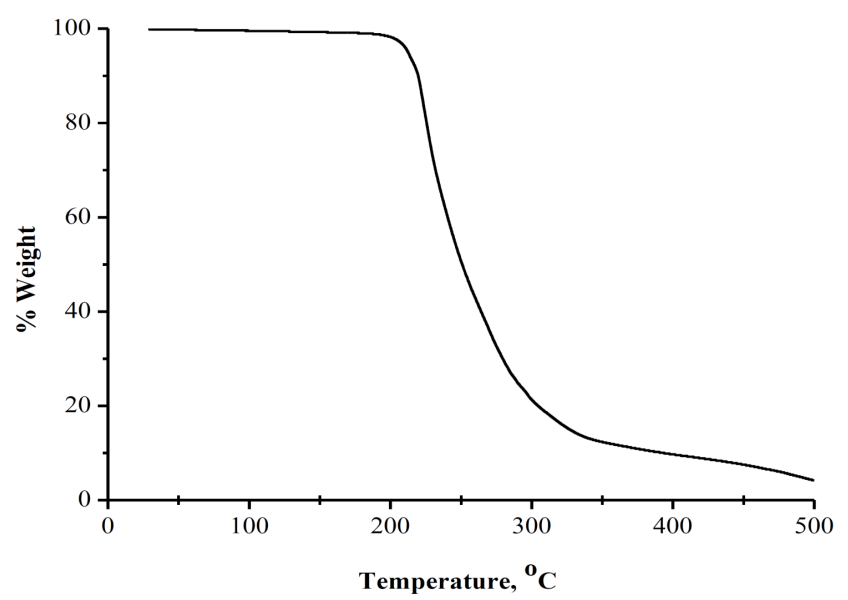

Fig. 4. Thermogravimetric curve of AMPS-pyridine.

\section{3. ${ }^{1} H N M R$}

Chemical shift values (Fig. 3) confirmed the structure of the resulted salt. In this figure, both AMPS and pyridine chemical shift values are included. Methylene $\left(\mathrm{CH}_{2}\right)$ group hydrogens bonded to $\mathrm{SO}_{3} \mathrm{H}$ can be seen at $3.20 \mathrm{ppm}[8,10,12]$, while the main chain hydrogens signals present at 1.27 and $1.40 \mathrm{ppm}[8,10,12]$ and NH hydrogens can be seen at $4.66 \mathrm{ppm}$ [12]. The peaks observed in the region $7.96-8.78 \mathrm{ppm}$ correspond to pyridine [13]. In the pure pyridine spectrum (figure is not given), the signals were observed in the region $7.3-8.61 \mathrm{ppm}$.

\subsection{Thermal behavior}

Thermal character of AMPS-pyridine was analyzed by TGA (Fig. 4) and DSC (Fig. 5).

It was reported that $-\mathrm{SO}_{3} \mathrm{H}$ groups decompose between 250 and $300^{\circ}[8,14]$. When classic ionic liquids evaluated in terms of thermal stability, their decomposition temperature can vary between $300-400^{\circ}$ [15]. The weight loss of AMPS-pyridine was found to be 1.7, 49.3 and $78.7 \%$ at 200,250 and $300^{\circ}$, respectively, which can be assigned to the degradation of $-\mathrm{SO}_{3} \mathrm{H}$. Weight loss became $90.3 \%$ at $400^{\circ}$. Effect of anion can be more dominant than the cation on the thermal stability of ionic liquids [16]. 

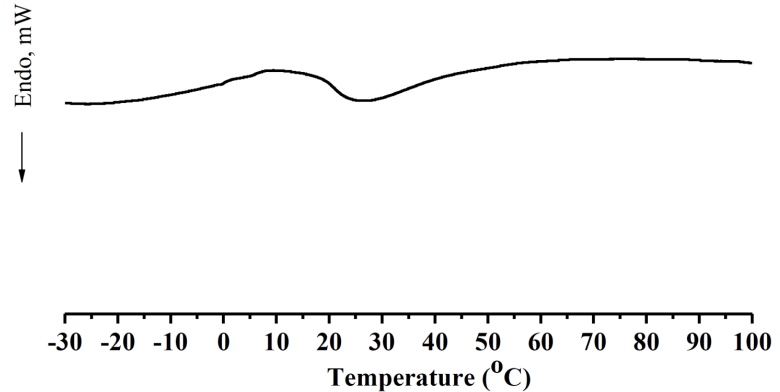

Fig. 5. DSC thermogram of AMPS-pyridine.

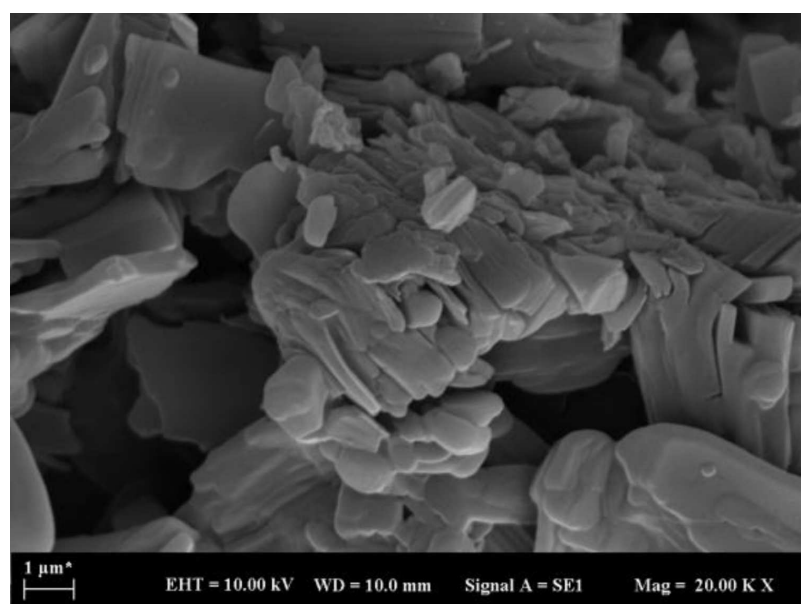

Fig. 6. SEM image of AMPS-pyridine.

In the present study, it can also be concluded that AMPS is more efficient on the thermal behavior. In the DSC thermogram, the observed glass transition of AMPSpyridine is about $18^{\circ}$.

\section{5. $S E M$}

Figure 6 depicts SEM analysis of AMPS-pyridine. Morphology of AMPS-pyridine is compatible with a salt structure.

\section{Conclusion}

An ionic liquid based on AMPS and pyridine was prepared and a comprehensive characterization study was performed to verify salt structure and to investigate its thermal behavior. Important observation was its solid state at room temperature. This study showed that AMPS-pyridine may have great potential for solid ionic liquid studies.

\section{Acknowledgments}

This work was supported by Scientific Research Project Coordination Unit of Istanbul UniversityCerrahpaşa. Project no.: FBA-2016-20100.

\section{References}

[1] X. Yang, Y. Fang, X. Li, K. Zhang, Y. Cui, B. Zhang, G. Yin, e-Polymers 14, 335 (2014).

[2] D. Mecerreyes, Progr. Polym. Sci. 36, 1629 (2011).

[3] P. García-Gutiérrez, R.M. Cuéllar-Franca, D. Reed, G. Dowson, P. Styring, A. Azapagic, Green Chem. 21, 4100 (2019).

[4] J. Parnica, P. Kesa, J. Kovac, M. Timko, M. Antalik, Acta Phys. Pol. A 126, 276 (2014).

[5] L. Balo, Shalu, H. Gupta, V.K. Singh, R.K. Singh, Electrochim. Acta 230, 123 (2017).

[6] S. Paţachia, Ch. Friedrich, C. Florea, C. Croitoru, eXPRESS Polym. Lett. 5, 197 (2011).

[7] N.L. Mai, K. Ahn, Y.-M. Koo, Process. Biochem. 49 , 872 (2014).

[8] P. Bhardwaj, V. Singh, S. Aggarwal, U.K. Mandal, J. Macromol. Sci. A 46, 1083 (2009).

[9] T. Weng, J. Guo, X. Li, et al., Design. Monom. Polym. 17, 140 (2014) .

[10] F. Rosa, J. Bordado, M. Casquilho, J. Appl. Polym. Sci. 87, 192 (2003).

[11] M.E. Castro, M.J. Percino, V.M. Chapela, M. Ceron, G. Soriano-Moro, J. Lopez-Cruz, F.J. Melendez, Int. J. Mol. Sci. 14, 4005 (2013).

[12] H. Jamshidi, A. Rabiee, Adv. Mater. Sci. Eng. 2014, 728675 (2014).

[13] V. Dzhagan, I. Lokteva, C. Himcinschi, X. Jin, J. Kolny-Olesiak, D.R.T. Zahn, Nanoscale Res. Lett. 6, 79 (2011).

[14] S. Çavuş, J. Polym. Sci. B 48, 2497 (2010).

[15] T. Erkoç, L.M. Sevgili, S. Çavuş, Open Chem. 17, 564 (2019).

[16] G. Laus, G. Bentivoglio, H. Schottenberger, V. Kahlenberg, H. Kopacka, T. Röder, H. Sixta, Lenzing. Ber. 84, 71 (2005). 